\title{
Social presence and dishonesty: perceptions from security guards
}

Susan Siebenaler, Andrea Szymkowiak, Paul Robertson, Graham Johnson, and Jan Law

This is the authors' accepted version of this conference paper. The final publication is available at Springer via https://dx.doi.org/10.1007/978-3-319-58484-3

Siebenaler, S., et al. 2017. Social presence and dishonesty: perceptions from security guards. In: FF-H Nah \& C-H Tan (eds), $\mathrm{HCl}$ in business, government and organizations: supporting business: 4th International Conference, HCIBGO 2017: proceedings. Cham: Springer, pp. 264-281. 4th International Conference on $\mathrm{HCl}$ in Business, Government and Organizations, Vancouver, Canada, 9-14 July. 


\title{
Social Presence and Dishonesty: Perceptions from Security Guards
}

\author{
Susan Siebenaler ${ }^{1}$, Andrea Szymkowiak ${ }^{1 凶}$, Paul Robertson ${ }^{1}$, Graham Johnson ${ }^{2}$, and \\ Jan Law ${ }^{1}$ \\ ${ }^{1}$ Abertay University, Dundee, UK \\ ${ }^{2} \mathrm{NCR}$, Dundee, UK \\ s.siebenaler@live.abertay.ac.uk, a.szymkowiak@abertay.ac.uk, \\ p.robertson@abertay.ac.uk, graham.johnson@ncr.com, \\ j.law@abertay.ac.uk
}

\begin{abstract}
Self-service technologies within retail enable customers to scan, bag and pay for their items independent from staff involvement. The use of self-service, due to its nature of reducing social interaction between customers and staff, has been implicated in creating opportunities for thefts to occur. However, the perception of social presence, such as induced by surveillance, induces customers to show more prosocial behavior. As security personnel are at the forefront to deal with dishonest customers, we conducted semi-structured interviews with security guards in two major supermarkets in the UK to assess factors surrounding theft, with a view to identify operational or technological opportunities to address theft. Our findings show that the perceived motivational and situational factors contributing to theft are complex. We conclude that surveillance in its current form does not appear to provide a sufficient social presence to prevent potential theft at Self-Checkouts (SCO). Future research could focus on additional surveillance measures to induce social presence, such as technological implementations in the SCO itself.
\end{abstract}

Keywords: Self-service, Social Presence, Surveillance, Retail

\section{Introduction}

Self-service technologies have been increasingly adopted over the past two decades, and include self-service kiosks within airports, hotels, retailers, cinemas and, more recently, fast-food restaurants. The main driver for this is to offer speed and convenience to the consumer. Within retail, self-service checkouts (SCOs, see Fig. 1.) enable customers to scan, bag and pay for their items, often without assistance from staff. For convenience, SCOs are usually located near to the shop exit, as their use typically represents the completion of a customer's shopping.

Retail staff involvement at the SCO area is limited to assisting customers, for example, to approve the purchase of age restricted items, such as alcohol, or to help with any technological issues. The effects of this overall lack of interaction with a member of

adfa, p. 1, 2011

(C) Springer-Verlag Berlin Heidelberg 2011 
staff (social presence) at SCOs is of growing interest to criminology and consumer behavior researchers, as it opens new avenues of conduct for customers [7, 17]. Leading theories from social psychology have previously influenced the social setting within a retail environment from opportunities of interaction with staff to awareness of security to the proximity to other customers $[20,29,34,36,38]$. However, the introduction of technology to the retail sector has been implicated as creating opportunities for theft [7]. Nevertheless, there is little research available regarding the prevalence of theft or shrinkage in stores who adopt self-service compared to those that do not [9], and many companies do not share their findings [7, 9]. However, a recent survey [23] has shown that stores that use SCO are more likely to experience theft than those that do not. Given the increase in the use of self-service technology globally, the benefits of self-service far outweigh its costs. At the same time, and for the benefit of retailers, there is a need to understand potentially novel forms of dishonest behavior arising from the use of new technology.

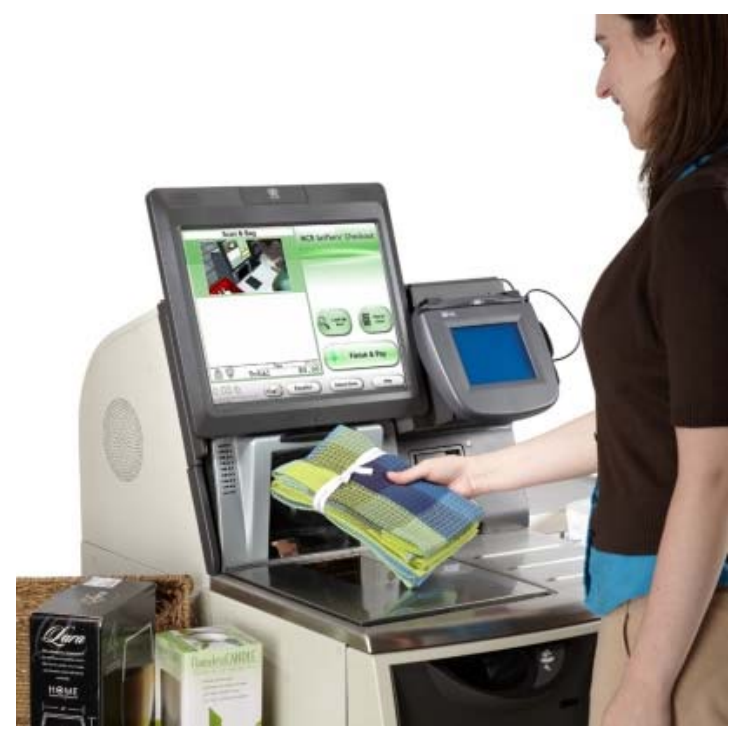

Fig. 1. Self-service checkout

The aim of the current study was to explore the current scenarios of dishonest retail customer behaviors at self-service, and to identify opportunities that may arise from these scenarios to address shrinkage. As it was not feasible within our field study to interview dishonest customers in relation to thefts at SCO, store security guards were interviewed with regard to their perceptions of customer dishonesty at SCOs. As security guards have the means (and role) to monitor dishonest customer behavior in detail, either in person or via closed-circuit television (CCTV), their perceptions and insights can provide valuable information on the factors surrounding theft at SCOs, with a view to identifying approaches to combat customer dishonesty. In the following sections, we will briefly review the research on customer dishonesty, the effects of surveillance and social presence, followed by a description of our study. 


\subsection{Customer theft}

Recent estimates suggest that customer theft accounts for $35 \%$ and internal theft for $33 \%$ of shrinkage, with process failures and inter-company fraud making up the remaining 32\% [7]. The figures appear favorable or even stable, compared with earlier estimates reported in 2004 [4] of $48 \%$ (Europe) and 31\% (US) shrinkage attributed to customers, and 40\% in 2002 [21] and 1984 [6], respectively. Figures may vary across the years and more widely by country [4], however, it appears reasonable to suggest that shrinkage has been and continues to be an ongoing challenge for retailers. This is also reflected in the earlier estimate that as many as $60 \%$ of customers have said that they have shoplifted at some point in their lives [25, 26]. There is an ongoing need to investigate and address underlying factors for shrinkage, and explanations may be sought from theories in criminology.

The Rational Choice perspective [14] focuses on contextual factors and decision making, rather than the psychological profiles of offenders to explain the motivation of crime. It suggests that potential offenders weigh up the costs and benefits of committing a crime, and make a rational choice based on the dominance of one factor. In the context of SCOs, customers weighing up the likelihood of being detected stealing may be inclined to take the risk, as they can blame any wrongdoing as a fault of the machine or process if they are caught, which Beck [7] defines as the "self-scan defence" (p. 212). Thus, the perceived cost of being caught may be reduced as the system may potentially be blamed for any 'mistakes' due to operational factors.

Extending the idea that decision making is the critical component in committing crime, the Crime Triangle put forward by Clarke and Eck [13] suggests that the occurrence of a crime depends on three factors: 1) a target with opportunity available, 2) the ability to obtain a product in a specific place, and 3) the desire of the offender to complete the crime. Eliminating one of these factors may prevent the crime. For example, increased surveillance, security tags, and employee positioning can address available opportunity.

\subsection{Surveillance and social presence}

There has been an increasing number of surveillance measures to reduce crime within retail over the past few decades [37], indicating that theft continues to be an ongoing issue. Historically, counteracting theft in retail has been addressed by introducing a social presence in a variety of ways including formal surveillance, e.g., CCTV, the presence of security guards and staff, or informal surveillance, such as mirrors or lights, to maximize visibility and encourage positive social interaction [31]. The importance of surveillance is also evidenced by the finding that shoplifters themselves perceive formal surveillance as one of the biggest deterrents for stealing [12].

\section{Social presence.}

The presence of others influences our behavior in everyday activities. Social presence has been defined as the perception of another real or imagined being or psychological 
involvement with something or someone in mediated communication [11,32], but definitions vary [28]. In the context of this study we use the definition of social presence in the widest sense as the perception of another. Social presence induces individuals to alter their behavior to give a positive impression [31] or increases self-awareness linked with prosocial behaviors [30]. The presence of others, such as other customers, even if we do not interact with them, may still influence our behavior $[2,19]$ and may influence decision making in a retail context [1]. Social presence can also be introduced by virtual characters or embodied agents (as co-presence) [e.g., 3] affecting human behavior. Thus, we would expect that the perception of a social presence on the part of a customer - even in the absence of direct interaction with staff - would increase the likelihood of honest behaviors to some extent.

Social presence - or its absence - may be relevant from two perspectives for the current study. Firstly, to the extent that customers may perceive a reduced social presence at a SCO itself due to limited staff interactions, the likelihood for prosocial behavior may decrease, resulting in a higher likelihood of dishonest behaviors.

Second, as already mentioned, historically, social presence has also been induced by the introduction of formal surveillance, such as CCT and security guards, which may affect customer behavior. However, research finding are often inconclusive with respect to the effectiveness of formal surveillance to affect crime [15].

\section{CCTV.}

Formal surveillance, such as represented by CCTV and store security guards, have been popular methods used to deter thefts for many years and are seen to be effective by managers [24]. However, Beck and Willis [10] argued that customers may have become inured [8] to traditional CCTV and it may no longer be an effective measure of theft prevention, although it may still be useful for confirmation of a suspected theft. As intentional shoplifters perceive formal surveillance as a major deterrent, they are highly intent on avoiding it [12], giving credence to its effectiveness; if CCTV can be avoided though, its efficiency as a deterrent will naturally be impaired.

\section{Security guards.}

Security guards are the most widespread and recognizable form of surveillance to prevent crime in public places [33]. Kajalo \& Lindblom [24] reported that security managers perceive the use of store security guards to be the most effective formal surveillance method.

The effectiveness of the use of security guards as a social presence in crime prevention has been explored in previous research [37], however, their effectiveness after the implementation of self-service technologies has not yet been fully evaluated.

As security guards are a vital element of store security, this research considers their perceptions of customers and their role in relation to customer theft at self-service checkouts. We were particularly interested in how security guards perceive customer 
behavior surrounding theft, how supported security guards feel in their ability to supervise checkouts, and their thoughts on technological implementations to support their role. The findings from the research may enhance knowledge of the nature of dishonest behavior at SCOs, and inform technological or operational opportunities. This knowledge may ultimately lead to the identification of measures that can support security and store staff in their role and reduce shrinkage for retailers.

\section{Method}

\subsection{Participants}

Six security guards (five males and one female) from two major UK supermarkets participating in the study were interviewed on the store premises. Four of the security guards were located at one store and two at the other. Their experience in security ranged from 12 months to 21 years and their ages varied between 23 and 46 years.

\section{$2.2 \quad$ Setting}

Both stores were of moderate to large size for the UK, with a size of 45,000 square feet and 67,000 square feet, respectively, and located in urban shopping centers. One store had one self-service checkout area containing ten SCOs located near the main door (67,000 sq. ft.). The other store had two separate SCO areas containing six SCOs in each (i.e. a total of twelve within the store), with one area positioned at the main door and the other nearer the back end of the store (45,000 sq. ft.). In each of the stores, security guards were typically placed near the entrance of the main door, with a view of the SCO machines.

\section{$2.3 \quad$ Procedure}

Interviews with security guards took place either during work or break time in private staff rooms within the work premises with permission of the store. The security guards had been provided with information on the study, i.e., to explore aspects of customer behavior at SCOs, by the store managers, and prior to the actual interview. All six security guards volunteered to take part in the research. All staff agreed for their interviews to be recorded and a typical interview lasted about 20 minutes. Participants were debriefed on the nature of the study at the end of the interview.

\section{$2.4 \quad$ Results}

Semi-structured interviews allowed for security guards' (SGs) opinions and attitudes to surface, which provided cues for further prompting and discussion that formed the basis of the following analysis. Responses were transcribed and then coded using NVivo software to identify occurring themes. In order to assess the reliability of the coding, 
two coders performed the analysis. Inter-rater reliability for the key themes was confirmed as the average Cohen's Kappa, $\kappa=.882, p<0.01$, which indicated a very good overall agreement between the two coders [27].

These themes were then grouped into higher-order categories, i.e., antecedents of theft, factors surrounding committed theft, after the (suspected) theft, thus preserving a logical order of activities related to theft, as well as staffing roles and measures as to how to address theft.

\section{Antecedents of theft.}

In line with their job description, all SGs stated that monitoring, i.e. "watching" was one of the most important parts of being a security guard, to identify suspicious behavior and thefts, and meet store policy guidelines for stopping someone suspected of theft. A typical day in the life of a security guard may include a variety of security activities, including store and alarm checks, making random patrols, and monitoring CCTVs and customer activity.

1.1 Customer characteristics. SGs reported that many customers who are caught stealing usually act alone, however, many customers act in a group, with one customer trying to distract a staff member.

"Either/or but on the whole - individuals. One person will walk and distract, but majority have been alone." (SG3)

With respect to monitoring activity at SCO, most SGs perceived that the intention of theft could be identified from a customer's behavior.

"If watching, you can see it [the intent to steal], they [the customers] usually look around themselves, always looking for the position of the person in charge of the selfservice checkouts." (SG1)

"[The customers] look around a bit nervous, they make mistakes, maybe testing the water." (SG3)

However, at the same time, all SGs pointed out that there is no 'stereotypical thief' as far as the demographic of the customer is concerned.

"It can be anyone." (SG5)

"[There are] all different types [of] people you would never expect." (SG4)

"[There is] not a stereotype, such as your average drug user. Everyone has this perception, but it's not." (SG3) 
More specifically, SGs identified a variety of customers types that may steal, ranging from school kids to the elderly to affluent customers, as and if the opportunity presents itself.

"Opportunistic thieves at different time of the day. School kids before and after school." (SG3)

“Banned a granny from store [for stealing].” (SG4)

"Folk walk out at the chance opportunity regardless [of] whether they have plenty of money to pay for it. Nine times out of ten it's just opportunity and it's someone that's 'well to do'." (SG2)

The motivations of customers that steal were not perceived to be uniform, but could be categorized in three different motivations, the first arising from financial hardship and need, and the second being attributed to financial gain.

"People are needy and desperate, stealing for their kids. Or you get ones stealing [...] like, whisky to resell.” (SG2)

A third motivation for theft SGs identified appears to be less associated with a premeditated intent to be dishonest, but rather a consequence of situational factors that may occur, for example, when customers need staff assistance, but staff are busy helping other customers:

“They [the customers] wouldn't steal otherwise if the wee lassie [staff] wasn't busy. I think they just get irate that they are waiting a length of time [...] and they are needing help. Frustration is a big part of it." (SG2)

"People may steal through frustration.” (SG3)

To the extent that frustration is associated with lack of technological assistance or staff, which thereby provides an opportunity to be dishonest, addressing both of these factors could be an important dimension in theft prevention.

The association between opportunism and dishonesty is discussed in more detail in the next section as a separate category.

1.2 Busyness, opportunism and staff. Opportunism seems a major factor in relation to thefts at SCO, be it associated with intent or with frustration. Unsurprisingly, all SGs stated that more thefts occur at SCOs when the store is busy.

"It [theft] tends to happen at busier times of the day because there are a lot more people for the one cashier to deal with, so they see the opportunity and take it." (SG6) 
"Busier days [are] easier for a thief, as [there is] more for the one cashier [means SCO staff] to deal with. If quiet, it's one on one, they won't do it. If busy, greater risk [of theft occurring].” (SG3)

"It's a lot easier to steal at self-scan than from [traditional staffed] checkouts because there is one person - 5/6/4 machines - they [staff] cannot see everything." (SG1)

The next comment is also noteworthy, as most SGs reported that more thefts occur at SCOs compared to staffed checkouts:

"Yes, [theft] more prone through SCO than manned. Because they are manned there's a personal interaction. Do get the odd one at manned [checkout], nesting, push through or walk through. SCO gives option of saying 'it's not my fault, it didn't scan', and [customers] can try to deceive camera by looking as if they are making payment, and worker is fooled as they are watching over six checkouts as opposed to one, so customer interaction is less; therefore [there is] more opportunity for an opportunistic thief before realisation sets in." (SG3)

SGs clearly perceive SCO staff members struggling to supervise multiple SCOs. And also expressed sympathy with the SCO staff, as they are seemingly put in a difficult situation of having to juggle many customers at busy times:

"Speaking from experience things happen; people walk away, abandon them [the SCOs], they won't scan something, put it in bag. It's a bit much to ask to have attention on all eight [SCOs] and you often find they [staff] get the blame. I have covered it and it's a hard job. One on one with a cashier - if there's chance of error then the person [staff member at cashier checkout] is more responsible than SCO [staff member]." (SG4)

The comments also hint at the responsibility SGs ascribe to SCO staff. While a traditional staffed checkout (cashier) has the sole responsibility for the purchasing transaction with the customer, SCO staff are responsible for multiple interactions at the same time, which appears to induce a dilution of perceived responsibility for the SCO staff due to perceived pressure. This is also illustrated by the following quote:

"A weight mismatch comes up on SCO - if girls [SCO staff] are busy they just clear it; they don't look in the bag so there is pressure on the staff." (SG5)

Having discussed customer characteristics and the busyness at SCOs associated with lack of staff assistance (social presence) providing opportunities for theft, SCO layout was also identified as a factor associated with dishonest behavior, and presents the final theme in this category.

1.3 Layout of SCOs. SGs identified the layout or design of the SCO as a component that could be relevant in addressing thefts. Stores where the SCOs are arranged in two 
parallel rows with customers and staff located in between those rows are particularly troublesome since when a staff member helps one customer, s/he has his/her back to half of the other checkouts, which means that the other SCOs are not monitored. This arrangement makes it easier for thefts to occur, since social presence or the effect of watching is reduced.

Many SCOs are also situated at the entrance to the shop making it easy for a quick escape for thieves.

"Fact that it's near the door. [Thieves] will always go to bottom one coz they are right next to the door. Common sense - by the time they get to me at the door the lassie [SCO staff] could have shouted for me to stop them, but they are straight out the door; the nearer they are the door the better. Better having one bank or two banks up the top. It's a quick exit." (SG1)

2. Factors surrounding committed theft.

2.1 Methods of theft. SGs noted that SCO is easy to trick. Customers are perceived to adopt a variety of methods to shoplift, such as concealing items, swapping bar codes or leaving the store without paying, which clearly shows intent on part of the customer.

"[It is] quite easy to deceive the machine." (SG3)

“Walking off without paying." (SG6)

"Concealment of the item. Ticket swapping. Scan cheaper. Make-up easy to conceal." (SG4)

"Two weeks ago we had a girl scanning one thing with two things in hands, so [she] scanned one thing, put the other one behind and both in the bag".

“Ticket swapping with reduction stickers.” (SG5)

"Scanning bananas for £1 and putting down steaks.” (SG2)

Concealing items, and swapping bar codes are methods shoplifters may adopt irrespective of which method of shopping they adopt, i.e., these methods are not exclusively linked to the use of SCOs. Indeed, these actions may most likely occur while the customer is still in the middle of the store. However, there are unique types of theft associated with SCO, such as scanning cheaper items instead of expensive one, or simultaneous scanning of two items, as expressed in the last comment. Due to the control the customer has SGs perceive there are more opportunities for theft to occur compared to traditional checkouts. 
"More chances and opportunities; [the customers] can make it look like they are paying or not paying for some. Can't get away with that at a cashier unless you conceal it before the till or if the cashier was in on it." (SG4)

This last comment hints at the possibility of a staff member being complicit in dishonest behavior, i.e., 'sweethearting'. Historically, sweethearting occurs when a staff member facilitates friends, family or colleagues to steal by not scanning their goods or by providing illegitimate discounts and it has been associated with shrinkage [7]. Sweethearting was not flagged up as a major factor associated with SCO use by the SGs we interviewed, but it is not possible to exclude this as a method of theft, just as it would occur with traditional staffed checkouts.

2.2 Type and value of stolen items. SGs stated that they have seen an increase in thefts of high value items such as electrical items and make-up and everyday items such as fresh produce and expensive meat.

"Expensive electrical items and expensive alcohol and clothing." (SG4)

"Usually it's just their daily shop; it can be milk and bread and stuff." (SG1)

Customers tend to use the 'scan \& bag' method of theft where they scan a cheap item and bag an expensive one, or they will weigh the item and select loose veg/fruit when it should be a steak.

2.3 Types of excuses/customer accountability. SGs noted that customers that have been caught stealing indicate it was a mistake, however, this appears to be similar irrespective of how customers shop, i.e. irrespective of SCO use.

"We always get that story [i.e., that customers indicate it is a 'mistake' when they get caught] whether they have been through checkout or not. They turn it around to be our fault, but that's their guilt; makes them more guilty." (SG5)

"The smarter dressed will say it’s a mistake." (SG4)

However, SGs recognized that there may be a 'grey area' where customers may indeed accidentally make a mistake.

"A lot of times it [mistake] can happen, aye. Most the times they are chancing their arm." (SG5)

In this case, the role of CCTV becomes important to confirm whether a customer has intent to steal, or whether indeed the customer merely made a mistake.

"Yes, they [customers] do [make mistakes]. Until I check back the CCTV I can't actually comment on that." (SG2) 
“Case dependent. CCTV can see if it’s been a genuine mistake or not.” (SG3)

In this case, the formal surveillance measure, which has historically been seen to deter theft, is mostly used for confirmation of dishonest intent. The role of surveillance is discussed in the next category.

\section{After the (suspected) theft.}

As SGs noted, some thieves may be professional, but some may be opportunistic. Once a customer is suspected of theft, SGs will look at the CCTV footage to assess a suspect's body language/behavior throughout the store to create a clearer picture whether they have acted in a suspicious manner prior to a theft, such as looking to where the member of staff is before concealing an item (see also 1.1 Customer characteristics in 1. Antecedents of theft).

3.1 CCTV. CCTV can be very useful in helping see whether a theft appeared to be on purpose or not and can be used as evidence for prosecution. However, thefts tend to be over and done with quickly and the perpetrator has left by the time a member of staff is able to alert security and the CCTV can be analyzed.

"By the time they have seen that there has been a walk off we will look at [CCTV] footage but that person is long gone." (SG5)

CCTV in store does not always allow SGs to view entire interactions with SCOs due to their positioning. SGs are in the uncomfortable position that, with a short distance between a SCO and store exit, any alarms regarding potential theft may be raised too late by a member of staff.

3.2 Police involvement. SGs generally felt that not much will happen to those who face prosecution after having been caught for alleged stealing. SGs state that thieves who have planned on stealing at the SCOs are unlikely to pay fines that they receive, and police involvement may not be an effective deterrent for them. Opportunists will make excuses regarding the technology of the SCOs, as they will either pay for their items or say they will be back to pay for them and then never return. This then makes managers reluctant to contact police for every theft that occurs at SCOs.

"Manager doesn't usually want to pursue it; if you bring the manager down then they don't want to do anything about it” (SG1)

Thus, security guards are put in a difficult position, having to balance their perceived duties with store policies.

3.3 Store policy and accountability. To stop a customer suspected of theft, SGs have to follow a particular policy involving store management. SGs feel that the policy can restrict their ability to deal with thefts efficiently. 
"Would I go and stop myself without a member of staff ... not with [store name] policies, because we would be penalised regardless of whether we were right or wrong." (SG2)

It seems that SGs at times may not feel supported by the store policy in their perceived role. Associated with this, SGs state they are made heavily aware of the repercussions of falsely stopping someone, as it can lead to newspaper articles and ultimately give bad press for the store which they feel could impact on their job.

"Have to think about reputation and false arrest. False arrest can lead to local papers and can be a bad thing." (SG1)

SGs appeared to be very aware of their store policy and how false arrests may lead to negative repercussions for them personally. This appeared to leave SGs feeling torn between fulfilling their job role and protecting their job. Clearer guidelines for the role and rights of SGs may address this issue. With new technology, for example, by the introduction of random checks before customers reach the exit (as is done for 'scan while you shop technologies' via 'random basket checks') may allow them to be more confident in their role. However, random product checks may be difficult to accept by customers.

\section{Staffing roles.}

Customers ask SGs for assistance in removing clothing tags etc. which takes away from their role as a security guard, meaning thefts may be more likely to occur as they are impaired in the ability to monitor for criminal activity.

"Sometimes by yourself at the door operating cameras and still have to check all keys and door seals. Fire exit doors with security seals, key checks for locked areas given out then given back at end of day" (SG4)

"Problems dealing with alarm goes off at front door, because of tags being left on [items]" (SG6)

SGs state that they can become frustrated with SCO staff if they feel they are not vigilant enough to detect thefts. SGs also stated that manned checkout staff who do not correctly remove security tags can waste a lot of the security guards' time as this leads to door alarms going off and unnecessary checks needing to be made. Clearer guidelines for job roles and expectations of staff members may reduce these issues occurring and disrupting the role of the SG.

5. How to address theft.

SGs offered some suggestions to reducing thefts at self-service checkouts. All stated that more vigilance would reduce thefts at self-service checkouts. Better technology was also stated as being likely to reduce thefts at self-service checkouts as they were 
too easy to trick. Also the SCOs positioning in the store was described as providing a quick exit (i.e. when the SCO is close to the exit) and making it easier for thieves to get away and difficult for security guards to stop them.

As a concluding question, the interviewer explored SGs' thoughts on whether technological implementations on the SCO itself may affect thefts, such as screen cameras. Security guards felt that CCTV on a SCO could be effective if perceived by the customer.

"I think if customers could see it [camera at SCO] and were more aware they were being watched it definitely would.” (SG4)

However, there was also a realization that shoplifting is an ongoing problem, with measures to counteract it lagging behind.

"[...] in general thieves are always adapting and evolving, whether it be a trolley pusher - it doesn't matter what it is. [Thieves are] always going to find ways round it. If they get caught one way, they will share information and find a new way to do it." (SG1)

"They [thieves] are always one step ahead. You are catching up with them all the time because they just think of something new." (SG5)

\section{Discussion}

This study explored factors around customer dishonesty at SCOs from the perception of security guards (SGs), with a view to identify possible opportunities to address shrinkage in retail. SGs' responses were grouped into five main categories, antecedents of theft, factors surrounding committed theft, what happens after the (suspected) theft, staffing roles, and how to address theft, which we discuss in turn.

Antecedents of theft. SGs provided a number of responses with respect to the type of customer committing theft. SGs suggested that there is no 'stereotypical' thief, in that shoplifters vary in age demographics and apparent wealth, which is in line with the inconsistent findings regarding shoplifter demographics others have noted [18]. Potential offenders reveal themselves rather by their body language than their demographic [18], e.g. by scanning the store for staff or other surveillance, which was also noted by SGs in the current study, who reported potential thieves can be spotted by the way they monitor where store staff are positioned at SCO.

There was an overall agreement from SGs that there were more thefts at SCOs when the store was busy and that there were more thefts at SCOs overall, compared to traditional manned checkouts. All security guards stated that it was easier to steal using SCOs due to only one member of SCO staff being generally present. These findings are consistent with those of Creighton et al. [16] who found that SCO staff reported feeling under pressure when SCOs are busy, as they are impaired in their ability to watch for 
thefts and assist customers at SCOs. Store staff also felt this increased the risk of thefts occurring [16], which in turn mirrors the perceptions of security staff in the current study.

The findings suggest that the implementation of a social presence, for example, via cameras within the SCO area, or indeed on/at the SCO itself [16], or strategically placed staff within the SCO area, could provide an opportunity to increase surveillance perceived by the customer, especially when the shop is busy. As an alternative, camera systems that could automatically monitor a customer's behavior to flag up suspicious customer activity to staff would represent a technical solution to spot potential suspect behavior, and is in line with, for example, biometric technology implementations.

SGs perceived that some consumers may steal because of frustration, for example, when they have to wait for staff because staff are assisting customers elsewhere. Frustration has been implicated in theft at $\mathrm{SCO}$ [35] in a recent study and is noteworthy as a motivator, as it can be speculated that frustrated consumers may not be habitual shoplifters. The blurry line between initial intent and theft happening through frustration is interesting to the extent that frustration may increase the desire to steal, which represents one aspect of the Crime Triangle [13]. This would suggest that addressing frustration may be the critical factor for customers in this category, as it could be expected that customers were not initially intent on stealing, yet were somehow tempted into it.

Frustration experienced at SCO may also be addressed by, for example, training staff to deal with frustrated customers effectively, or indeed, providing more staff at SCO for customer assistance. In addition, the implementation of technology that could flag up if a customer is likely to be frustrated may be helpful in this instance, for example, when a SCO process may take too long. Interface design may also address some of the user frustrations, for example, by introducing anthropomorphic agents or indeed real staff in an image area on the screen to induce social presence to deal with customer frustration.

Finally, the layout of the store was flagged up as critical for committing thefts, as SGs pointed out that more thefts occur at SCOs near 'the doors'. This suggests modifying SCO layout, by, e.g., increasing the distance between SCOs and the exit.

Furthermore, social presence when exiting the store could be enhanced by introducing mirrors [31], embodied agents or indeed robots [22] or cameras [16] displaying the customer's footage in the SCO area.

Factors surrounding committed theft. SGs noted that SCOs are easy to trick and that customers use a number of methods to steal, including concealing items by simultaneously scanning two items, with one item being concealed, or scanning cheaper instead of more expensive items (e.g. bananas for steaks). The responses are consistent with recent findings by Taylor [35], reporting many techniques of theft, such as selecting items that are less expensive than the loose items being weighed, or selecting cheap cooking tomatoes instead of expensive vine tomatoes, etc. The methods of theft are creative and SGs noted that they are always trying to 'catch up'.

With respect to the type of item stolen, SGs noted an increase in thefts of high value items (electrical, make-up, clothing) but also everyday items. Typically, customers scan a cheap item and bag an expensive one. While bar codes can be swapped in the store, before a customer even proceeds to a staffed or SCO checkout, the difference in price 
between cheap and expensive items is probably bigger at SCO than at staffed checkouts. At staffed checkouts, staff may actually notice the difference if the price for an expensive item is too low. However, at SCOs swapped price tags may go unnoticed until a SCO staff member actually checks the prices and receipts.

Our findings are consistent with a study by Bamfield [4], who also noted that items that were reported stolen were typically of high value, a relatively small size, and often designer brands or in great or regular demand by the public. Those findings point again to a wider demographic of customer, refuting the idea of a 'stereotypical' thief motivated by financial need as outlined above.

SGs pointed out that most thieves caught stealing, irrespective of whether they use SCOs or not, tend to indicate that it was a 'mistake', however, they also acknowledged that honest mistakes could have been made by customers. SGs state that the majority of people who are suspected of theft at SCOs will blame the technology as there are grey areas of security that allow for this to happen, which means it can be difficult to prove customer intent. This is consistent with research from Beck [7] who calls this the self-scan defence. With respect to the thief with intention to steal, others [35] have noted that that a large majority of thieves admit that they stole initially by accident, but that shoplifting became a routine after that, especially when it was easy to do the first time. Here, staff vigilance, but also increased tagging of items or technological implementations at $\mathrm{SCO}$, such as item recognition, may be useful means to address the first experience of a successful theft.

After the (suspected) theft. SG stated that, once a customer is suspected of theft, the role of CCTV is to confirm that a theft has occurred. The finding that CCTV in its current form is not effective in deterring thefts is noteworthy, given that shop-lifters perceive the presence of formal surveillance effective ad deterrents [12]. This points to the implementation of more effective ways of inducing perceived surveillance - and staff assistance - for customers at SCO to prevent theft. For example, adaptions such as onscreen cameras may increase a sense of social presence and reduce the likelihood of such behaviors occurring [30], especially if this camera surveillance cannot be avoided by the customer using the SCO.

The findings also suggest that SGs are under many pressures from store policies and other expectancies of their role, as they have to abide by store policies once a customer is suspected of theft. Having to perform their role as Security Guards effectively has to be balanced with the potential damage to the store's reputation, if a false arrest is made. Some expressed feeling demoralized by the lack of authority they have when someone is caught and a suspect is not further prosecuted. That this may be a valid perception is supported by findings from recent research [5] showing that only a small proportion of shoplifters are apprehended and prosecuted, and is consistent with an earlier study [21] which noted only $24 \%$ of all apprehended shoplifters being prosecuted.

SCOs may increase the number of instances of 'walking' off with goods that have not been paid for [5] and SGs in the current study commented on this too. Clear position of the SCO could assist security guards and members of staff in reducing thefts occurring, as they would have more time to evaluate and act on suspected 'walkers' or thieves in general. Taylor [35] also highlights the matter of reduced staff presence at SCOs as a factor that can influence thefts, suggesting that implementations that induce presence 
may reduce thefts, in line with what was earlier discussed regarding the store layout above. However, Hoffman et al. [22] state that initial effects of a social presence may reduce if customers learn that the risk of repercussions is limited.

Staffing roles. SGs can become frustrated with SCO staff if they perceive staff are not vigilant enough to detect thefts. SG also stated that staff who do not correctly remove security tags can waste a lot of the security guards time, as this leads to door alarms going off and unnecessary checks needing to be made. This is impacting on their task to monitor for criminal activity. There was an overall agreement among SGs that SCO staff were under pressure when SCOs were busy and they could not 'do everything' or be held responsible for thefts when the SCO area was busy, however, there was also the perception that this impacted on their own role too. This suggests that clear guidelines should assist both SCO staff and security guards, in particular, when the store is busy, as it appears that both staff groups are distracted from being an effective social presence at this time [16], and this may be affecting their working relationships. The findings suggest that security implementations within a SCO could assist both SCO staff and SGs, perhaps allowing customers to de-tag items after valid payments have been made.

How to address theft. SGs stated a number of factors to address theft, ranging from better vigilance, to better technology at SCOs and story layout with respect to SCO positioning further away from the door. The theme of 'watching' was alluded to multiple times. Clearly, SGs perceive surveillance as effective in deterring thefts, and so do shoplifters [12], with store managers [24] perceiving security guards to be the most effective surveillance method. However, given that an increasing number of formal surveillance measures are implemented to address crime [39], it is questionable to which extent these are indeed successful, given the shoplifting figures generally, and the absence of exact figures of theft at SCOs [Taylor 16].

It should be noted that SGs commented positively on the implementation of cameras on SCOs, provided the customers were aware of this type of surveillance. As shoplifters tend to avoid cameras (if they are aware of them), implementing them where customers cannot avoid them, i.e. at the SCO itself, may be useful, as noted above. The perception of a social presence has been linked to more positive behavior via an enhanced selfawareness [30,31] and should be considered. Given that customers have to direct their attention to the $\mathrm{SCO}$ while conducting their transactions, a highly visible camera on the SCO screen may not go unnoticed, and thus, may raise their awareness of social presence.

\section{Conclusions}

The thoughts and views of security guards are important in understanding perceived customer motivations and behaviors surrounding theft at SCO. The research presented clearly suggests that security guards feel security measures for reducing thefts at SCOs could be improved.

Thefts may occur for multiple reasons and involving self-service in customer transactions may create a complex situation, with many factors at play. Customers may over- 
or undercharge themselves, and they may or may not be aware of it. The control that customers experience at SCO may create situations where theft can occur by accident. However, theft that can be conducted easily, whether intentional or non-intentional, may predispose individuals to repeat this behavior [35], and thus should be avoided. Factors that bring about theft, such as the busyness of the store combined with opportunity for stealing at $\mathrm{SCO}$, should be recognized and could be addressed by, for example, enhancing surveillance temporarily during busy times. Others have noted that the implementation of social presence has a positive effect on human behavior [30, 31], and this should also be the case with regard to reducing theft, be it via enhancing staff presence or other, technological implementations at SCO (cameras, mirrors, embodied agents etc.).

Given that we interviewed staff on their work premises, the cooperation of staff and the stores was paramount to conducting the study. This research is part of a larger research project focused on the effects that a social presence may have within a retail environment, and in particular, theft. One limitation of our study was the relatively small sample, thus, findings may not be generalizable to different cohorts of security guards or indeed, different countries or types of stores. However, the interviews allowed us to get a comprehensive, in-depth view of the perceptions of security guards in relation to theft, which was valuable in understanding the factors that may be addressed to prevent theft. Given that our findings were also consistent with the work of others hints at the validity of the discussed findings.

SGs considered surveillance as one of the most important factors to address theft. However, our study indicated that a constant social presence is difficult to achieve consistently and effectively. Given that social presence has been shown to be effective in modifying people's behavior [e.g., 1, 2, 19, 30, 31] it would be reasonable to suggest that future research should consider variations on how social presence is implemented in retail. Methods could include the implementation of technology within SCOs or varying social presence over a period of time to avoid habituation effects. With technological advances within the retail sector there is great potential to address theft to ultimately benefit businesses and customers, and their experiences, and also support the staff working in retail.

Acknowledgments. We would like to thank the stores and security guards for their participation in this study. We would also like to thank NCR for supporting this project.

\section{$5 \quad$ References}

1. Ahmad SN (2016) The role of Social Facilitation Theory on consumer decision making: A conceptual framework. American Journal of Management 16: 80-89

2. Argo J, Dahl D, Manchanda R (2005) The influence of a mere social presence in a retail context. Journal of Consumer Research 32: 207-212

3. Bailenson JN, Swinth K, Hoyt C, Persky S, Dimov A, Blascovich J (2005) The independent and interactive effects of embodied-agent appearance and behavior on self-report, cognitive, and behavioral markers of copresence in immersive virtual environments. Presence: Teleoperators and Virtual Environments 14:379-93 
4. Bamfield J (2004) Shrinkage, shoplifting and the cost of retail crime in Europe: a crosssectional analysis of major retailers in 16 European countries. International Journal of Retail \& Distribution Management 32: 235-241

5. Bamfield J (2012) Shopping and Crime. Palgrave Macmillan, Basingstoke

6. Baumer T, Rosenbaum D (1984) Combating Retail Theft: Programs and Strategies. Butterworth, Stoneham, MA

7. Beck A (2011) Self-scan checkouts and retail loss: Understanding the risk and minimising the threat. Security Journal 24: 199-215

8. Beck A (2015) Developments in Retail Mobile Scanning Technologies: Understanding the Potential Impact on Shrinkage Loss Prevention. ESRC, Leicester

9. Beck A, Hopkins M (2016) Scan and rob! Convenience shopping, crime opportunity and corporate social responsibility in a mobile world. Security Journal. 2016.

10. Beck A, Willis A (1999) Context-specific Measures of CCTV Effectiveness in the Retail Sector. Surveillance of Public Space: CCTV, Street Lighting and CrimePrevention, Crime Prevention Studies Series 10: 251-269

11. Biocca F, Harms C, Gregg J (2001) The Networked Minds measure of social presence Pilot test of the factor structure and concurrent validity. Paper presented at the 4th annual international workshop on Presence 2001 USA, Philadelphia

12. Carmel-Gilfilen C (2013) Bridging security and good design: Understanding perceptions of expert and novice shoplifters. Security Journal 26: 80-105

13. Clarke R, Eck JE (2014) Become a Problem-solving Crime Analyst. Routledge, London

14. Cornish DB, Clarke RV (eds) (2014) The Reasoning Criminal: Rational Choice Perspectives on Offending. Transaction Publishers, London

15. Cozens PM, Saville G, Hillier D. (2005) Crime prevention through environmental design (CPTED): A review and modern bibliography. Property Management 23: 328-56

16. Creighton S, Johnson G, Robertson P, Law J, Szymkowiak A. (2015) Dishonest behavior at self-service checkouts. In: International Conference on HCI in Business, August 2015 Springer International Publishing, pp. 267-278.

17. Dabholkar PA, Bagozzi R P (2002) An attitudinal model of technology-based self-service: moderating effects of consumer traits and situational factors. Journal of the Academy of Marketing Science 30: 184-201

18. Dabney DA, Hollinger RC, Dugan L (2004) Who actually steals? A study of covertly observed shoplifters. Justice Quarterly 21: 693-728

19. Dahl D, Manchanda R, Argo J (2001) Embarrassment in consumer purchase: The roles of social presence and purchase familiarity. Journal of consumer research 28: 472-81

20. Harrell GD, Hutt MD, Anderson JC (1980) Path analysis of buyer behavior under conditions of crowding. Journal of Marketing Research 17: 45-51

21. Hollinger RC, Davis JL (2002). 2002 National Retail Security Survey: Final report. Gainesville, FL: University of Florida.

22. Hoffman G, Forlizzi J, Ayal S, Steinfeld A, Antanitis J, Hochman G, Finkenaur J (2015) Robot presence and human honesty: Experimental evidence. In: Proceedings of the Tenth Annual ACM/IEEE International Conference on Human-Robot Interaction, ACM, Portland, pp 181-188

23. Home Office (2015) Crime against Businesses: Findings from the 2014 Commercial Victimisation Survey. Home office, London

24. Kajalo S, Lindblom, A (2010) The perceived effectiveness of surveillance in reducing crime at shopping centers in Finland. Property Management 28: 47-59

25. Klemke, LW (1982) Exploring adolescent shoplifting Sociology and Social Research 67: 59-75 
26. Kraut RE (1976) Deterrent and definitional influences on shoplifting Social Problems 25: 358-368

27. Landis JR, Koch GG (1977) The measurement of observer agreement for categorical data. Biometrics 33: 159-174

28. Lowenthal P (2009). The evolution and influence of Social Presence Theory on online learning. In: Kidd TT (ed) Online education and adult learning: New Frontiers for Teaching Practices. IGI Global, Hershey, PA, pp.124-139

29. Nicholson M, Clarke I, Blakemore M (2001) Multichannel consumer behaviour in the retail fashion sector: Toward a longitudinal ethnography. Paper presented at the 11th International Conference on Research in the Distributive Trades, Vol 1, EIM Business Policy Research, Tilburg, NL

30. Pfattheicher S, Keller J (2015) The watching eyes phenomenon: The role of a sense of being seen and public self-awareness. European Journal of Social Psychology 45: 560-566

31. Reynald DM, Elffers H (2009) The future of Newman's Defensible Space Theory linking defensible space and the routine activities of place. European Journal of Criminology 6: 2546

32. Short J, Williams E, Christie B (1976). The Social Psychology of Telecommunications. John Wiley \& Sons, London

33. Sklansky DA (2006) Not your father's police department: Making sense of the new demographics of law enforcement The Journal of Criminal Law and Criminology 96: 12091243

34. Stoltman JJ, Morgan FW, Anglin LK (1999) An investigation of retail shopping situations. International Journal of Retail Distribution Management 27: 145-153

35. Taylor E (2016) Supermarket self-checkouts and retail theft: The curious case of the SWIPERS Criminology Criminal Justice 16: 552-567

36. Uzzell DL (1995) The myth of the indoor city. Journal of Environmental Psychology 15: 299-310

37. Welsh BC, Farrington DP, O'Dell SJ (2010) Effectiveness of public areas surveillance for crime prevention: Security guards, place managers and defensible space. Swedish National Council for Crime Prevention, Stockholm

38. Willis P (1990) Common Culture. Open University, Milton Keynes

39. Yaniv G (2009) Shoplifting, monitoring and price determination. Journal of Socio Economics 38: $608-10$ 